\title{
Enfermedad y daño. Etiología y tratamiento de la viruela entre las sociedades nativas de Araucanía (fines del siglo XVIII)
}

\author{
Juan Francisco JiMÉNEZ \\ Universidad Nacional del Sur (Argentina) \\ jjimenez@uns.edu.ar \\ Sebastián L. Alioto \\ Universidad Nacional del Sur (Argentina) \\ salioto@uns.edu.ar
}

Recepción: 23 de junio de 2013 / Revisión: 11 de noviembre de 2013

Aceptación: 4 de diciembre de 2013 / Publicación: diciembre de 2014

\section{RESUMEN}

En el año 1791, una epidemia de viruelas que afectaba a las poblaciones indígenas de la frontera de Arauco -situadas al sur del río Bío-Bío en Chile- se constituyó en seria preocupación para las autoridades coloniales de Concepción, debido al temor de que los habitantes hispano-criollos de la región pudieran verse infestados. Actuando de acuerdo con el paradigma del contagio, impusieron un cordón sanitario que los aislara de los nativos y sugirieron a éstos que hicieran otro tanto. Conscientes además de que la peste era atribuida a la hechicería hispana, se apresuraron a ofrecer remedios y asesoramiento médico, con la finalidad de demostrar que no mediaba voluntad de provocar daño. Las respuestas de las distintas agrupaciones evidenciaron la coexistencia de una variedad de perspectivas con respecto a la etiología de la viruela y a los posibles cursos de acción: desde una concepción personalista que la atribuía a la actividad de los brujos, hasta una llana admisión de la propia incapacidad para tratarla que derivaba en la aceptación de las medicinas españolas. El cuadro general muestra un modelo nativo de la enfermedad, a la vez conservador e innovador, complejo y dinámico.

La descripción de los eventos en un expediente que luego se envió a España y las referencias contenidas en otras fuentes coloniales permiten el examen del episodio epidemiológico utilizando como contexto comparativo las conceptualizaciones actualmente vigentes entre los mapuche, pero también el análisis de las concepciones dominantes al respecto entre los propios españoles a fines del siglo XVIII.

Palabras clave: viruela, indígenas, etiología, brujería, contagio, aislamiento, terapias, frontera, Chile, siglo XVIII.

\section{Illness and daño. Etiology and treatment of smallpox among native societies of Araucanía (late $18^{\text {th }}$ century)}

\begin{abstract}
In the year of 1791, a smallpox epidemic which affected the Indian populations of the Arauco frontier -south of Bío-Bío river in Chile- worried the colonial authorities of Concepción, due to the fear that the Spanish inhabitants of that region could also get infected. Acting according to the contagion paradigm, they imposed a cordon sanitaire in order to isolate them from the Natives, and suggested these do the same. Also, conscious that the plague was commonly attributed to Spanish witchcraft, they hurried to offer medicine and medical advice, in order to show there was no will to cause damage. The responses
\end{abstract}


of the different Indian groups demonstrated the co-existence of a wide variety of perspectives regarding the etiology of smallpox and the possible paths of action: from a personalist conception which attributed it to witches' activities, to the admission of their own inability to find proper treatment, which led to the acceptance of Spanish medicines. The general picture shows a native model of the illness that is both conservative and innovative, complex and dynamic at the same time.

The description of those events, found in a folder which was later sent to Spain, and the references contained in other colonial documents, allow the examination of the epidemiologic event using as a comparative context the conceptualizations now current among the Mapuche. They also allow the analysis of dominant conceptions concerning illness among the Spaniards in the late eighteenth century.

Keywords: Smallpox, Indians, Etiology, Contagion, Witchcraft, Isolation, Therapies, Frontier, Chile, $18^{\text {th }}$ century.

Sumario: 1. Introducción. 2. Modelos etiológicos nativos. Enfermedades y brujería. 3. Características de la viruela. Tratamientos indígenas. 4. El brote de 1791. Su origen en la provincia de Concepción (1788-89), la difusión hacia territorio indígena y las medidas adoptadas. 5. La venganza del obispo. 6. La complejidad de las respuestas indígenas frente a la ayuda ofrecida. a) Sacerdotes y sangrías. b) Yerbas y medicamentos. c) Medidas preventivas. 7. Conclusiones. 8. Referencias bibliográficas.

\section{INTRODUCCIÓN}

En el año 1791, el presidente y capitán general del Reino de Chile, Ambrosio O'Higgins, intentaba organizar trabajosamente un Parlamento General que reuniera a todos los indígenas independientes que vivían al sur del río Bío-Bío para asegurarse, como era costumbre, la paz y la concordia entre las distintas parcialidades, y de todas ellas con la corona española. En ese contexto, un brote epidémico puso en riesgo su proyecto político: la viruela, que atacó primero las poblaciones fronterizas españolas de la región de Concepción, pasó luego hacia los asentamientos reche/mapuche ${ }^{1}$. La presencia de la enfermedad entre los indios generó en las autoridades fronterizas coloniales una doble preocupación. Por un lado, debido al temor de que la peste reingresara en territorio "cristiano" y los habitantes hispano-criollos de la isla de la Laja, que habían sorteado la primera oleada, pudieran verse infestados. Para evitarlo, y actuando de acuerdo con el paradigma del contagio, los funcionarios impusieron un cordón sanitario que los aislara de los nativos y sugirieron a estos que hicieran otro tanto.

Por otro lado, O’Higgins y sus subordinados temían que los nativos atribuyeran la enfermedad a la hechicería hispana, y en venganza reaccionaran con violencia. Se apresuraron entonces a ofrecer remedios y asesoramiento médico, con la finalidad de demostrar que no mediaba voluntad de provocar daño. Las respuestas de las distintas agrupaciones evidenciaron la coexistencia de una variedad de perspectivas con respecto a la etiología de la viruela y a los posibles cursos de acción: desde una concepción personalista que la atribuía a la actividad de los brujos y por ello desdeñaba las recomendaciones coloniales, hasta una llana admisión de la propia incapacidad para

1 Los pobladores de la Araucanía se autodenominaban "reche" (la verdadera gente) en los primeros tiempos de la conquista; en el siglo XVIII el etnónimo se transformó en "mapuche”, con un mayor énfasis en el dominio del territorio, Boccara, 1998. 
tratarla que derivaba en la aceptación de las medicinas españolas en algunos casos, o de las medidas de aislamiento y profilaxis en otros. El cuadro general muestra un modelo nativo de la enfermedad, a la vez conservador e innovador, complejo y dinámico.

\section{Mapa 1}

Fuertes españoles y reducciones indígenas en la frontera araucana hacia 1791

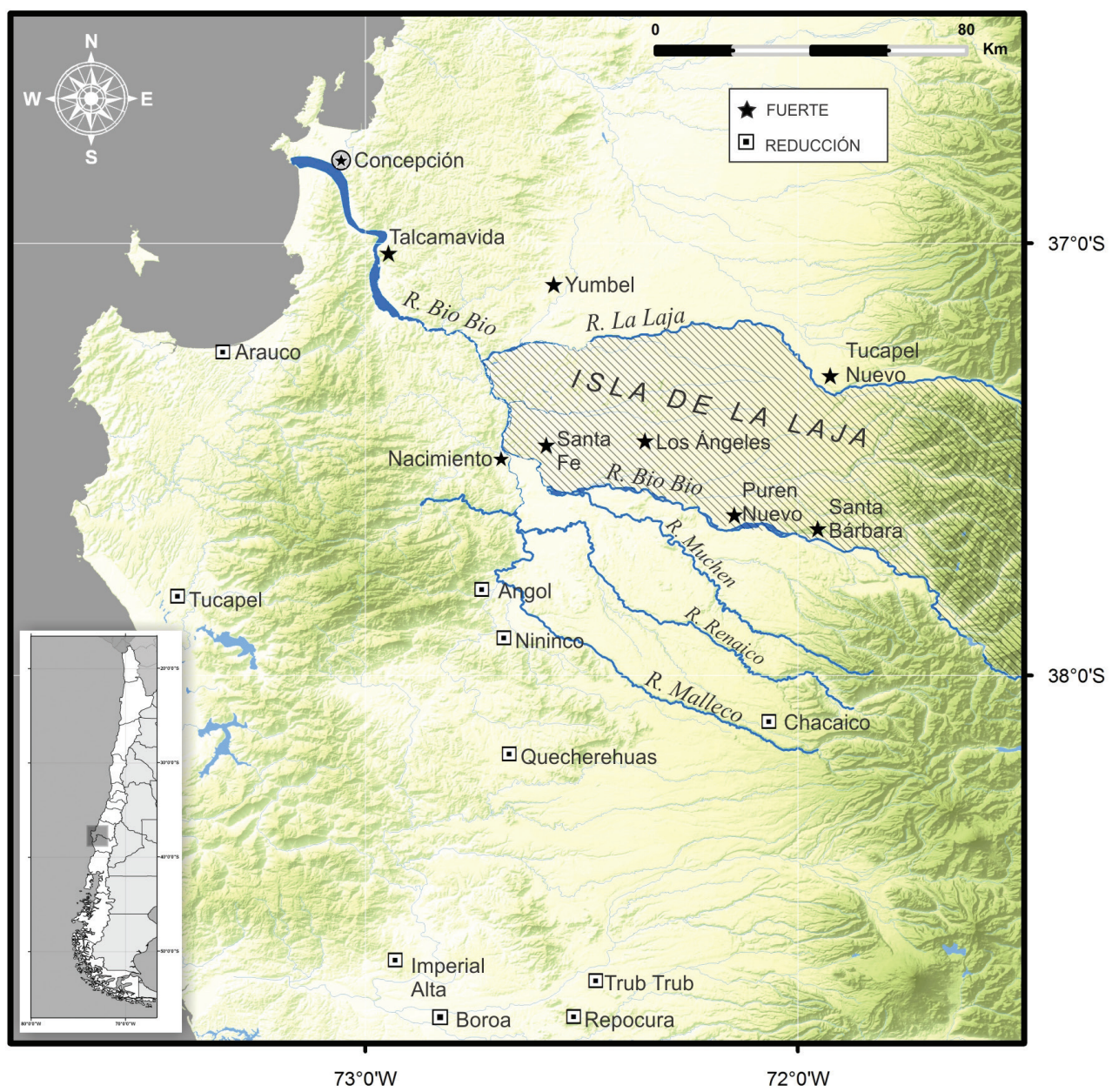

Si bien la epidemia fue una más de las que regularmente afectaban a las poblaciones nativas en la América Meridional y como tal nada tuvo de excepcional, lo que resulta de extraordinario valor como fuente histórica es el expediente generado con motivo de su desencadenamiento. El contenido de esos papeles ya fue aprovechado por Fernando Casanueva, quien lo utilizó principalmente para estudiar el efecto de la 
viruela sobre las inestables relaciones político-diplomáticas de la frontera ${ }^{2}$. Nuestro trabajo, en cambio, enfatizará la importancia de las lecciones que el expediente nos dejó sobre cuestiones médicas. En él encontraremos la posibilidad de incorporar una rica e inusual perspectiva acerca de la diversidad de las creencias nativas sobre la enfermedad y sus orígenes, y de la pertinencia o no de las medidas sanitarias y los tratamientos empleados para curarla. Podremos apreciar también la capacidad nativa de evaluar en forma racional la eficacia de diferentes tratamientos médicos y de basar en ello su aceptación o rechazo.

Estas cuestiones suelen permanecer opacas o invisibles en los documentos, dado que se hallaban fuera del conocimiento o del interés de los funcionarios escribientes; es por eso que, mientras existen varios trabajos etnográficos que se ocupan de ellas entre los mapuche contemporáneos, faltan estudios históricos que las analicen en contextos anteriores, en especial cuando los indígenas aún mantenían su autonomía y por lo tanto una mayor capacidad de decisión en su relación con el Estado colonial. Uno de los elementos clave del éxito mapuche en su larga resistencia contra el régimen colonial radicó en su capacidad de apropiarse de rasgos culturales hispanocriollos. Pero mientras que la incorporación de cereales, animales o metales son bien conocidos, no lo es el proceso de evaluación que precedió a la aceptación o al rechazo de ideas, técnicas y tratamientos sanitarios provenientes de los "cristianos". En este expediente puede verse cómo los nativos eran capaces de entablar una comparación, incorporar lo que pareciera adecuado y rechazar de manera fundada aquello que no lo fuese. Sirve a la manera de una pequeña ventana iluminada a través de la cual alcanzamos a vislumbrar complejas cuestiones más generales que casi siempre permanecen ocultas: ¿cuáles fueron las concepciones vigentes sobre el origen de la viruela entre los mapuche a fines del siglo XVIII? ¿Cuáles eran para ellos los tratamientos considerados adecuados para tratarla? ¿Qué tipo de ayuda que pudieran brindar los españoles se consideraba útil, y cuál no, y por qué? Todas estas convicciones acerca de la enfermedad, ¿eran uniformes y unánimes entre todos los grupos locales, o había diferencias entre ellos?

Pasaremos revista primero a nuestro conocimiento adquirido sobre los modelos etiológicos nativos desde el punto de vista histórico y etnográfico; luego, a las características de la viruela y los distintos tratamientos a los que los indígenas del vasto espacio fronterizo al sur del Imperio español echaron mano para morigerar sus efectos; y finalmente, analizaremos el contexto histórico del brote epidémico de 1791 y el significado de las respuestas indígenas.

\section{MODELOS ETIOLÓGICOS NATIVOS. ENFERMEDADES Y BRUJERÍA}

Desde el punto de vista de la etiología -o la teoría de las causas de la enfermedad-, la mayoría de las sociedades nativas americanas manejaban un conjunto de explicaciones que combinaban los sistemas médicos naturalistas y personalistas (según la

\footnotetext{
2 Casanueva, 1992 y 2000.
} 
definición de George Foster ${ }^{3}$ ). En los últimos, la enfermedad o desgracia es causada por la intervención intencionada de un agente. Estos agentes pueden ser: a) humanos (brujos, hechiceros); b) no-humanos (fantasmas, ancestros, espíritus malignos); o c) sobrenaturales (deidades, otras entidades poderosas). En cambio, en los sistemas naturalistas la enfermedad es resultado de la acción del frío, el calor, la humedad, ciertos vientos o el desequilibrio entre humores corporales ${ }^{4}$. En los primeros momentos de su contacto con las pestes introducidas por los europeos, los reche/mapuche elaboraron explicaciones de tipo personalista: la enfermedad fue atribuida a la intervención malintencionada de agentes humanos (por ejemplo, gobernadores, misioneros, obispos) que empleaban la brujería para difundir el daño entre ellos ${ }^{5}$.

En el siglo XVII las pestes fueron denominadas en conjunto "piru cutan" o enfermedad del gusano, y en el XVIII se acentuó el énfasis en la viruela: "piru cuthan: la peste de viruelas o qualquiera otra" 6 . Debemos a los jesuitas la traducción del término "cutan" o "cuthan" como "enfermedad", significado que empobrece su complejidad conceptual que nos es revelada, en cambio, por su actual utilización entre las comunidades mapuche. Estas aluden con ese término ("kutran") al estado en el que un individuo no puede relacionarse correctamente con los demás, ni se encuentra en condiciones de realizar sus tareas habituales, como resultado de múltiples factores, incluyendo la transgresión de un orden moral por parte del propio afectado 7 .

Hoy, las enfermedades son clasificadas según su origen y tratamiento en dos grandes categorías: "wingka kutran" (o enfermedades que proceden de los "wingka", o que se curan mediante la medicina occidental) y "mapuche kutran". Estas últimas se dividen en tres categorías: "re kutran", enfermedades naturales ajenas a cualquier intervención de un agente o fuerza intencional; "wenu kutran", enfermedades originadas en una infracción a las normas sobrenaturales; y "weda kutran", enfermedades provocadas por un agente -humano o fuerza sobrenatural maligna- con la intención de provocar un daño ${ }^{8}$.

Esa clasificación contemporánea codifica y expresa la experiencia histórica y el conocimiento acumulado por los/las machi del pasado y es probable que fuera el esquema de referencia utilizado por tales especialistas para identificar el origen de las enfermedades introducidas en el siglo XVI ${ }^{9}$. Inicialmente la viruela ingresó en la categoría de "weda kutran", es decir, de las enfermedades causadas adrede por un

3 FosTer, 1976, pp. 773-782.

4 Ibídem, p. 775.

5 Dada la constante continental representada por la creencia de que las enfermedades epidémicas postcontacto eran fruto de la brujería europea, un grupo tras otro, al sufrir su impacto, acusaron a diversos agentes (comerciantes, misioneros, incluso imágenes sagradas) de ser los difusores del mal por distintos medios.

6 Valdivia, 1684, s. p.; Febrés, 1765, pp. 596-597.

7 Citarella, 2000, p. 128.

8 Ibídem, pp. 129-130; ver también en el mismo sentido BaCigaluPo, 2001, pp. 44-52.

9 La continuidad entre los conocimientos de machis antiguos y sus descendientes contemporáneos está garantizada por una larga cadena de transmisión de maestro/a a discípulo/a, de un corpus elaborado de tradición oral: "Cada historia consiste en un corpus de narrativas rituales (historias, mitos, salmos, canciones, oraciones, etc.), conocimientos rituales, ritos y fiestas y comprende una gran variedad de códigos ideológico-simbólicos y prácticos. Estos códigos enseñan un conocimiento importante que está asociado con los ancestros y los seres supremos, y que ha influido y orientado las estrategias de los Araucanos para enfrentar eventos y situaciones de sus vidas rituales y seculares". Dillehay, 2007, p. 44, traducción propia. Ese corpus se ve incrementado 
agente maléfico. Las fuentes son claras al revelar la directa asociación que los reche encontraron entre viruela y brujería española ${ }^{10}$. Ya en 1561, el arribo del gobernador Francisco de Villagra a Chile coincidió con un brote de la enfermedad y los nativos no dudaron en acusarlo de provocarla para terminar con la lucha que entonces tenía lugar:

porque en desembarcando se inficionó el aire de tal manera, que dió en los indios una enfermedad de viruelas, tan malas, que murieron muchos de toda suerte, que fué una pestilencia muy dañosa, y por ella decían los indios de guerra que Villagra no pudiendo sustentarse contra ellos, como hechicero había traido aquella enfermedad para matarlos, de que cierto murieron muchos de los de guerra y de paz ${ }^{11}$.

Esta asociación entre contienda armada, hechicería y enfermedad fue anterior a la invasión europea: precisamente, una de las funciones de los/las machi era realizar actos de agresión "simbólica" contra los enemigos de su grupo ${ }^{12}$. En el contexto de la nueva situación de contacto, la novedad estuvo representada por la magnitud del ataque. Mientras que los shamanes eran capaces de "flechar" a un individuo por vez, los españoles parecían usar el equivalente ritual de un armamento de destrucción masiva, capaz de sembrar la muerte en cientos o miles de individuos. En 1611, durante el desembarco en La Serena de Juan Jaraquemada, recién designado gobernador de Chile, se rompió una botija llena de lentejas y los porteadores indios difundieron la noticia de que esa multitud de pequeñas semillas diseminadas era la fuente germinal a partir de la cual la enfermedad iniciaba su temida propagación para alcanzar luego el carácter epidémico y letal que la distinguía.

Sucedió acaso que entre las botijas de pólvora y miel, vino y aceitunas que del Perú se traen, venían algunas semillas y legumbres para este Reino, donde no las había; y quebrándose una de lentejas, semilla no conocida en estas Provincias y que tiene semejanza de viruelas, que por parecerse llaman comúnmente a este mal lentejuela creyeron que era semilla de viruelas que traía el Gobernador para sembrar estas Provincias y acabar con los indios por este medio. Persuadieronse a esto porque habían padecido antes un contagio grande viruelas, y luego pasaron la noticia a todas las Provincias para que defendiesen la comunicación de los españoles ${ }^{13}$.

con las experiencias de cada generación de machis, que lo utilizan como un esquema conceptual que sirve de marco de referencia para sus propias vivencias.

10 Las enfermedades causadas por la brujería eran (y siguen siendo) tratadas por machis en un ritual de curación denominado "machitun". Las primeras descripciones de este ritual datan del siglo XVII (VARGAS, 1891, pp. 392-393; Rosales, 1877, pp. 159-160; PinEdA Y BASCUÑ́n, 1863, pp. 158-161), y contamos con otras del siglo XVIII (CARVallo y Goyeneche, 1876, pp. 138-139, Molina, 1795, pp. 105-106). En la actualidad los rituales de curación conservan la misma secuencia y estructura básica que los descritos para los siglos XVII y XVIII. Pueden definirse como conjuros del mal acompañados de frotaciones con hierbas medicinales, y durante los mismos los/ las machis extraen el "daño" chupando o abriendo la parte afectada. La ceremonia se realiza en la morada del paciente, que es acondicionada a tal efecto, y se espera que a la misma asistan los familiares directos, parientes, amigos y vecinos del enfermo, que se hacinan en su interior. Esta aglomeración de personas en un espacio cerrado en la etapa de contagio facilita enormemente la difusión de la enfermedad. Para descripciones modernas del rito ver: Bacigalupo, 2001, pp. 84-87; Citarella, 2000, pp. 230-238; y FöERster, 1993, pp. 104-107.

11 Góngora Marmolejo, 1960, pp. 142-143.

12 Boccara, 1998, pp. 129-132.

13 Quiroga, 1979, p. 322. 
La claridad del texto transcrito demuestra cómo, aplicando un razonamiento analógico, los reche creyeron descubrir el origen del mal, relacionando un bien de procedencia extraña con el surgimiento de la epidemia. Así también, a comienzos del siglo XVIII en la cordillera de los Andes, los misioneros jesuitas fueron responsabilizados de utilizar la imagen de la virgen para difundir una peste de "cursos de sangre", posiblemente disentería ${ }^{14}$ :

Tambien casi por este mismo tiempo corrio en las tierras del norte i pehuenches una epidemia de cursos de sangre, que acabó con muchos indios. Sintieron los moradores de aquellas parcialidades tan cruel azote; i sin reconocer al autor principal que les aflijia, consultaron a sus brujos para saber la causa de sus males. Respondieron ellos, instigados sin duda por el demonio, que toda aquella calamidad les venia por haber pasado unos meses ántes el padre por sus tierras i haber llevado a Nahuelhuapi una señora española. Fué el caso que de la ciudad de Lima remitieron una hermosa imájen de la virjen para que se colocase en la primera iglesia que tuviese esta mision. Cuando pasó, lo supieron los indios del camino, porque no pudo ser tan en secreto. I ellos, alucinados con su cortedad, publicaron que el padre introducia en sus tierras aquella señora española para causarles algun grave $\mathrm{mal}^{15}$.

En ocasión de otra epidemia de tifus exantemático -o tabardillo- que estalló en el área de Valdivia durante el año de 1779, los indígenas volvieron a responsabilizar a un gobernador, esta vez el de la plaza de Valdivia. El misionero franciscano Miguel López informaba a sus superiores sobre los avisos que había recibido secretamente de un cacique de Panguipulli, quien en primer lugar recomendaba que ningún español viajase tierra adentro, "porq. ${ }^{\mathrm{e}}$ recelosos los Yndios que llebase la peste corria mucho riesgo lo matasen". La situación no concluía allí, pues los Puelches de ultra-cordillera amenazaban con atacar Valdivia en caso de verse afectados por la epidemia: "q. ${ }^{\text {e en la }}$ hora q. ${ }^{\mathrm{e}}$ dentrase la peste en ellos, venian à vengarse del Gov. ${ }^{\mathrm{r}}$ y españoles" ${ }^{\prime 16}$.

14 Laval cita el caso y lo incluye entre las epidemias de disentería en Chile: LAval, 2010, pp. 76-79. A veces las enfermedades eran descritas por sus síntomas, de manera que podían confundirse dolencias distintas; por ejemplo, bajo el título de "cursos de sangre", que podría hacer alusión a disentería, fiebre tifoidea o cólera. La clínica de la época tenía grandes dificultades en individualizar las distintas enfermedades y brotes epidémicos.

15 Olivares, 1865 , pp. 517-518.

16 Miguel Lopez, Suma y plan delos Yndios que habitan en esta Mis. ${ }^{\mathrm{n}}$ de Nra Sra del Pilar fundada en el Parage llamado Quimchilca. Quimchilca, 10-VII-1780. Archivo Franciscano de Chillán (en adelante AFCH), Vol. IV, f. 176. Esta peste era tabardillo o tifus, que había estado afectando los terrenos situados al sur del río Toltén. La identificación de ese mal en: Benito Delgado y Gerónimo Pérez, Plan de las Parcialidades de esta Mision de la Purissima Concep. ${ }^{\mathrm{n}}$ de Arique, y de los Yndios q. ${ }^{\mathrm{e}}$ hay en cada una de ellas. Arique, 2-VII-1780. $\mathrm{AFCH}$, Vol. IV, f. 164. Sobre su generalización, que no asoló únicamente la Misión de Arique sino otras dos de las misiones de la jurisdicción de Valdivia (San Francisco de Valdivia y San José de la Mariquina), Miguel Ascasubi, Ynforme Chronologico de las Misiones del Reyno de Chile. Chillán, 31-XII-1787. AFCH, Vol. V, ff. $82-114 \mathrm{v}$. 


\section{CARACTERÍSTICAS DE LA VIRUELA. TRATAMIENTOS INDÍGENAS}

El virus de la viruela ("Variola maior") que afectó a los pobladores de la región provocaba generalmente una tasa de mortalidad que rondaba el 30\%, y entre el $65 \%$ y el $80 \%$ de los supervivientes quedaban marcados con profundas cicatrices deprimidas, especialmente en el rostro. En poblaciones nativas americanas, el nivel de letalidad podía ser aún más alto: los cálculos de los observadores euro-criollos en general lo situaron por encima de un 50 por ciento. La viruela resultaba especialmente mortífera para los indios, porque debido al aislamiento continental no habían estado expuestos al virus; fue así que la tasa de mortalidad resultante constituyó una de las causas principales de su caída demográfica luego del contacto y siguió afectándolos periódicamente ${ }^{17}$.

Otro rasgo que la volvía temible, además del alto nivel de contagio, era su fase asintomática durante la cual un enfermo portaba el mal consigo varios días sin saberlo. Pueden distinguirse dos etapas en el desarrollo de la enfermedad. La primera consistía en un período de incubación que duraba de 12 a 14 días: el paciente no presentaba síntomas externos, se sentía y parecía sano, y no infectaba a otras personas. Luego sobrevenía la aparición repentina de síntomas de tipo gripal, fiebres, malestar, cefalea, postración, intenso dolor de espalda y con menor frecuencia dolor abdominal y vómitos. Dos o tres días más tarde, la fiebre bajaba y el paciente mejoraba temporalmente, pero enseguida surgían una serie de erupciones, primero en la cara, las manos y los antebrazos, y luego por todo el tronco. También aparecían lesiones en la mucosa de las fosas nasales y la boca que se ulceraban con rapidez, liberando grandes cantidades de virus en la boca y la garganta. En este momento, la posibilidad de contagio era máxima para quien se mantuviera en las cercanías del paciente, pues las pequeñas gotas de saliva que se expulsaban con la tos diseminaban el virus.

Aunque la morbilidad generó en los nativos de la región un previsible terror, luego de dos siglos de contacto algunas de las agrupaciones habían comprendido el modo de propagación y para neutralizarlo separaban a los enfermos del resto de la comunidad, dejándoles alimentos y bebidas:

Conocen que la viruela es contagiosa y así lo mismo es asomar entre ellos que dejan al paciente solo, se muda el toldo lejos y cada tres dias vienen algunos á ver los enfermos por varlovento, les dejan comida y bebida y prosiguen haciendo lo mismo con todos hasta que sanen ó mueran que es lo comun ${ }^{18}$.

17 Esto se vio agravado por el hecho de que los nativos americanos tenían un alto grado de homogeneidad inmunogenética, que provocaba que la incidencia del contagio entre personas no emparentadas equivaliera a la de parientes cercanos en Viejo Mundo, provocando una alta letalidad: BLACK, 1992, pp. 1739-1740. Algunos españoles también fueron conscientes de que la enfermedad atacaba en mayor medida a los indios, pero acordes a la teoría clásica de los humores todavía vigente en la época lo adjudicaban al temperamento "caliente" de los indígenas, y conjeturaban que "es mucho mas eficàz y activa su voracidad entre los Yndios por que su naturaleza y complexion ardiente sirve de material y pabulo que incrementa el incendio": Respuesta del Fiscal Dr. Pérez de Uriondo al Presidente de Chile. Santiago de Chile, 27-VII-1791. Archivo General de Indias (en adelante AGI), Chile, 197, f. 269v.

18 Aguirre, 1949, pp. 340-341. 
Al mismo tiempo que disminuía la propalación del mal, este tratamiento aumentaba las posibilidades de supervivencia del enfermo ${ }^{19}$.

El aislamiento de los enfermos resultaba crucial para cortar el contagio: un cautivo en uno de los malones contra la frontera de Buenos Aires en 1752 declaró que, habiéndolo aprisionado los indios a él y a su hijo, apenas vieron que este tenía viruelas abandonaron a ambos y a poco de caminar, encontraron a un indio en la misma situación:

y que como le hubiesen dado las Virguelas a dho. su hijo los dejaron a pie en medio Campo y se fueron, y despues que su hijo se medio alento se fueron ápie siguiendolos por el rastro á los dhos Yndios y llegaron aun toldo donde havian dejado vn Yndio enfermo de Virguelas y alli pararon y de alli fue de donde se huieron ${ }^{20}$.

Falkner describe la desesperación que asolaba a los grupos apresados por la epidemia, y asevera que en esas ocasiones la reacción más común era la huida del lugar donde habitaban y el abandono de los que no podían seguir el ritmo de marcha:

La viruela también [...], ha hecho más estragos entre ellos que la peste antigua misma, y es un flagelo que ha desolado pueblos enteros. Este mal es más funesto entre ellos que entre españoles o negros por su modo de ser, mala alimentación, falta de abrigo, remedios y el cuidado indispensable. Porque los parientes inmediatos de los que caen enfermos huyen, para escapar del contagio y los abandonan a perecer, aunque sea en un desierto. Hará cosa de 45 años que la numerosa nación de los Chechehets se contagió con este mal en las inmediaciones de Buenos Aires, y trato de huir de la peste retirándose hacia su tierra, que distaba unas 200 leguas, a través de desiertos inmensos. Durante la jornada dejaban por el camino a los enfermos, sus parientes y amigos, abandonados, sin quien los cuidara, y sin más amparo que un cuero que les atajase el viento y una tinaja con agua; y así se ven tan reducidos en número que apenas cuentan con 300 hombres de pelea ${ }^{21}$.

Aunque aislado, un paciente regularmente asistido tenía mayores posibilidades de sobrevivir. Por lo tanto, el hecho de que enfermaran simultáneamente casi todos los miembros de un grupo aumentaba la letalidad de la viruela, debido a la escasez de personas que brindasen alimento, agua y abrigo a los enfermos.

Otro método que aparece en las fuentes del lado occidental de la cordillera es mucho más radical -para decir lo menos-y consistía en eliminar al enfermo mediante el fuego. Al parecer era practicado por grupos Lafkenche. El botánico español Hipólito Ruiz, que visitó brevemente la costa de Arauco en 1782, escuchó que:

Si en alguno se advierte enfermedad contagiosa ó ha muerto de ella, le queman vivo ó muerto, con todos los muebles de su uso; y a veces los sacan al monte con todos

19 Cfr. Jones, 2003, pp. 732-733; Kelton, 2004, p. 64.

20 Declaración del cautivo Eusebio del Barrio, en Cabildo de Buenos Aires, Información presentada sobre la reducción de Pampas a cargo de la Cía. de Jesús. Buenos Aires, 11-VIII-1752. AGI, (Copias del Museo Etnográfico de Buenos Aires, carpeta J. 16), Charcas, 221, ff. 52v.-53.

21 FALKNer, 1957, p. 127. 
sus asistentes en la enfermedad y atados juntos los echan en una hoguera para que no contagien á los demas ${ }^{22}$.

Lo mismo narró el autor anónimo que acompañaba al obispo de Concepción Francisco Marán durante su desafortunado viaje de 1787: "Quando se grava una enfermedad epidemica los que componen la familia donde se ha introducido el âchaque perese incendiada y asi crén extinguir su gravacion" ${ }^{23}$. Y Molina, al ocuparse de la viruela en su Ensayo de la Historia Natural de Chile, agregó:

Los araucanos, libres aún de dicho mal, cuando saben que alguno de ellos se ha contagiado por haber comerciado con los españoles, prefiriendo la salud pública al bien particular, lo queman dentro de su propia casa mediante flechas incendiarias. Tales precauciones han atajado el contagio dentro de los términos ya expresados ${ }^{24}$.

Un enfermo de viruelas generaba pánico, y no era para menos si tenemos en cuenta el profundo riesgo de contagio. No obstante y como veremos, el aislamiento o el fuego no fueron las únicas respuestas posibles frente a la enfermedad: existieron otras que incluían varias formas de tratamiento.

\section{EL BROTE DE 1791. SU ORIGEN EN LA PROVINCIA DE CONCEPCIÓN (1788-89), LA DIFUSIÓN HACIATERRITORIO INDÍGENA Y LAS MEDIDAS ADOPTADAS}

El brote que afectó a los nativos en 1791 fue continuación de la plaga que en 1788 y 1789 afectó a la provincia de Concepción. Este territorio había permanecido mucho tiempo sin verse aquejado por la enfermedad, y de allí la alta tasa de mortalidad que ella generó. En fecha muy cercana a la epidemia, un autor desconocido observó lo siguiente:

En ambas epocas, y aun en otras posteriores la Ciudad de la Concepcion se viò siempre libre de este azote destructor de la humanidad, y con tal experiencia casi llegò à reputarse por invulnerable su suelo. Pero introducida desgraciadam. ${ }^{\text {te }}$ por los años de 1789 cundiò con tal furia que entre la ciudad y sus contornos arrebatò casi instantaneamente sobre dos mil y quinientas personas de todos sexos edad y condiciones; perdida à la verdad lamentable y irreparable en una capital de tan corta poblacion. Ynemdiatamente se introduxo el uso de la inoculacion por medio de un mulato de Santiago despachado por el Presidente del Reyno, pero ya muchos habian perdido la vida y las facciones del bello sexo, verdaderamente apreciables en aquellas provincias

\footnotetext{
22 RuIz, 1952, p. 221.

23 Anónimo, Breve idea del Caracter, Temperamento usos y costumbres de los Naturales, en cuio poder por nuestra desgracia hemos estado. Concepción, 15-XII-1787. Biblioteca Nacional de Chile, Sala Barros Arana [en adelante BNC-SBA], Manuscritos, Tomo 2 [Tomo 37 en la nueva numeración], f. 307.

24 MolinA, 1986, p. 35. Cosme Bueno abunda en igual sentido y agrega que la mudanza de sitio sucede a la quemazón: "Los indios araucanos dan fuego al rancho, en que está el enfermo de viruelas, y se mudan á otra parte" (Bueno, 1778, f. 7). Cfr. también: Anónimo, Descripción del Obispado e Intendencia de Concepción. S/1, s/f (ca. 1790). Archivo del Museo Naval de Madrid (en adelante AMNM) Ms. 121, Doc. 6, f. 173.
} 
habian sido en gran parte victimas de esta peste ${ }^{25}$.

También Francisco Xavier de Viana, integrante de la expedición de Alessandro Malaspina, aseguraba que sólo en la ciudad de Concepción, donde estuvo de paso, fallecieron en 1788 y 1789 unos 2.500 habitantes de un total de 6.000 que vivían en ella ${ }^{26}$.

En esa ocasión, la isla de la Laja $^{27}$ quedó libre del contagio y las autoridades, temerosas de que las partidas comerciales que todos los veranos ingresaban desde territorio indígena fueran portadoras de la enfermedad, decidieron tomar medidas para evitarlo. En el mismo oficio en que se informaba al presidente del "Reyno" Ambrosio O'Higgins sobre el brote de viruela entre los nativos, se mencionaban las medidas sugeridas para combatirla: el establecimiento de un cordón sanitario que contuviera la enfermedad al otro lado del Bío-Bío y el aislamiento de todos los enfermos que manifestaran síntomas ${ }^{28}$.

Las políticas de cuarentena y aislamiento implementadas por las autoridades de Concepción eran las recomendadas en una Real Orden del 15 de abril de 1785. Junto con ella, el Ministro de Indias José de Gálvez envió a las colonias un folleto con instrucciones acerca de cómo proceder durante un brote de viruelas ${ }^{29}$. La orden fue remitida por O'Higgins al gobernador de Valdivia, y este a su vez la cursó al Superior de los misioneros franciscanos ${ }^{30}$. Copias de la Real Orden y el adjunto debían ser distribuidos entre los "sujetos que mas convenga" -autoridades médicas, civiles y religiosas de cada jurisdicción-, en cuyas manos estarían las medidas a nivel local.

El folleto era en realidad un libro escrito por el médico Francisco Gil. Básicamente, el autor proponía mantener un sistema de lazaretos en donde los enfermos serían atendidos por personas que ya hubieran padecido la enfermedad y por lo tanto estuvieran inmunizadas, logrando de esta manera controlar su propagación ${ }^{31}$.

25 Anónimo, Descripción del Obispado e Intendencia de Concepción. S/1, s/f (ca. 1790). AMNM, Ms. 121, Doc. 6 , f. 157vta.

26 Ver Ferrer, 1904, p. 256.

27 Territorio fronterizo de forma triangular delimitado por los ríos de La Laja y Bío-Bío, y la cordillera de los Andes.

28 Por ejemplo: "Ha resultado el accidente en un Mozo que acompaño à dho Capitan Fontalva, y tambien en un Pehuenche de Billocura, sin poderse averiguar de donde lo contrajo este. El primero salio al Gualpon [sic] de la otra banda de la Laja, y el seg. ${ }^{\text {do }}$ se separo en lo interior de la montaña, en un Rancho al cuidado de un Dragon seloso, y con auxilios hasta concluir su Quarentena": Oficio del Intendente de Concepción Francisco de la Mata Linares a Ambrosio O'Higgins. Concepción, 17-VI-1791. AGI, Chile, 197, ff. 244-244v.

29 Son las instrucciones que echó de menos Fernando Casanueva: CASANUEva, 2000, p. 213.

30 Copia del oficio del Ministro de Indias José de Gálvez al Presidente de Chile. Valdivia, 8-III-1786. AFCH, Vol. VI, ff. 26-27.

31 Los ejemplares enviados eran de la primera edición de la obra: GiL, 1784. El Despacho Universal de Indias financió esa primera edición y se encargó de distribuirla por todas las dependencias coloniales: entre mayo y septiembre de 1785 se mandaron en total 3.500 ejemplares de la obra de Gil en tres tandas a todas las dependencias americanas junto con la Real Orden (ver Expediente Sobre la remision â Yndias de los Ympresos que tratan el modo de preservar â los Pueblos de Viruelas. Madrid, 15-IX-1785. AGI, Indiferente General, 1335). La obra alcanzó una gran difusión y fue re-editada en diversas ocasiones. 
En cuanto al cordón sanitario, se trataba de la aplicación de un antiguo método empleado para lidiar con la difusión de la peste surgido en las ciudades-estados italianas durante el siglo XIV ${ }^{32}$ y ampliamente utilizado a lo largo de los siglos XVIII y XIX.

El contagio hacia el lado indígena de la frontera se había debido probablemente al intercambio comercial, que era una de las vías más frecuentes, pues se trataba de una actividad que requería de la proximidad física de las personas involucradas ${ }^{33}$. Junto con la gente y las mercancías, la peste se expandía a través de las rutas comerciales y acompañaba al flujo de los objetos, atravesando las fronteras. Por eso mismo los españoles, temiendo el regreso de la viruela al norte del Bio-Bio, cortaron la entrada de partidas comerciales indígenas.

\section{LA VENGANZA DEL OBISPO}

Dada la asociación existente entre pestes y brujería ("kalkutun") orientada en la región a la presencia española, no resulta extraño que, en ocasión de la epidemia de 1791, un obispo (el de Concepción, a quien ya hemos mencionado) fuera considerado por algunas parcialidades responsable de provocarla, a raíz de circunstancias singulares que tuvieron lugar en años inmediatamente anteriores al brote. Así permite verlo el siguiente texto:

Aunque ninguno de estos socorros admitieron; se consiguio á lo menos que ellos hayan conocido la recta intención, y deseo de su bien con que se los Franquie, de que me mandaron dar muchos agradecimientos deponiendo el concepto de que ya se comensavan á impresionar, de como en venganza del insulto que hicieron los de Boroa, y de la alta Imperial, al Reverendo Obispo de la Concepcion quando pasava por allí á Valdivia se les havia introducido esta Peste, ofreciendo, que si les liberara de ella, restituirian las Alhajas q. ${ }^{\mathrm{e}}$ le saltearon ${ }^{34}$.

En Araucanía y la Cordillera, cuando una persona joven fallecía, los familiares recurrían a los servicios de un "llihua" ${ }^{35}$, quien en una ceremonia denominada "llihuatun" identificaba al agresor. La familia y los amigos del afectado procedían entonces a organizar un malón con el objetivo de castigar al "kalku" señalado:

32 CARMichael, 1991, pp. 213-256.

33 Los indígenas americanos también lo entendieron así. En muchas de las cosmologías nativas, la viruela y el comercio con los europeos estaban íntimamente relacionados; lo mismo sostuvo Henry Dobyns al señalar que una de las principales vías de difusión del virus era el traslado de personas y bienes con finalidades comerciales: Dobyns, 1992, pp. 215-222. Como señala Jackson refiriéndose a los casos del Paraguay y México, "las epidemias también se extendieron con las personas que viajaban de comunidad en comunidad portando la infección en sus cuerpos y exponiendo a la enfermedad a la gente susceptible. Estos contactos ocurrieron con mayor frecuencia a través de las diferentes formas en que la gente realizaba su comercio, acudía al trabajo en otras comunidades o por el movimiento de grupos de soldados": JACKSON, 2004, p. 137.

34 El insulto consistió en capturar al prelado y su comitiva y apoderarse de un cuantioso y rico equipaje y otras pertenencias de mucho valor. Oficio de Ambrosio O'Higgins al Marques de Baja Mar, Santiago de Chile, 13-XII-1791. AGI, Audiencia de Chile 197, fs. 240-240vta.

35 "Llihua"- el adivino, a quien consulta. "Llihuan, llilhuatun"- adivinar o predecir, e inventar a su modo. FeBRÉs, 1765, p. 541. 
Sé ha de advertir, que aunque estos Yndios admiten muerte natural en las Personas muy viejas, y decrepitas de las quales ya suelen dezir: acui ñi antù, ô poui thoquinantu se llegò su plazo, ô le llegò la hora; pero en los demas no admiten Muerte natural, sino que siempre enferman, ô mueren, porque les ha hecho daño algun Brujo: y para descubrir al Autor del Maleficio, toman un Regalo, ô Paga y van â consultar al Adivino, â quien ellos llaman Llihua. Este haziendo varios Papeles, y ridiculas ceremonias y dando vuelta â un Laurel (Canelo), comienza â llamar al Peuma (assi llaman al espiritu de Profecia, ô al Diablo) paraque baje, y le hable: despues de varias vueltas quando bien le pareze da un Salto haziendo el ademan de cogerlo y dando silbos, y mezclando palabras que ni el entiende por no significativas, finge q. ${ }^{\text {e }}$ se pone en consulta con el Peuma, y espera que le revele quien es el Brujo q. ${ }^{\mathrm{e}}$ le ha hecho daño al enfermo: luego adivina, y declara por Brujo â quien se le antoja. Sabido ya quien es el Brujo, ô Bruja, sin mas declaraciones, ni Justicia se juntan los Parientes (y otros) del enfermo: ô del Difunto, y acaban con toda la Familia, casa y hazienda de aquel miserable â quien le cayò tan infeliz suerte ${ }^{36}$.

Solía verificarse que los "llihua" señalasen a los culpables entre quienes habían tenido conflictos o enemistades previas con el difunto:

Para dar alguna apariencia de verdad a su adivinacion suelen informarse antes cautelosam. ${ }^{\text {te }}$ de las riñas, y enemistades que tuvo el Enfermo aunq. ${ }^{\mathrm{e}}$ aya pasado mucho tpô, y se inclinan por aquellas personas de quienes su declaracion se puede hacer mas creible $^{37}$.

En ese contexto, el rumor que asociaba la epidemia con las previas situaciones vividas por el obispo de Concepción constituía un serio motivo de preocupación, pues podía generar a corto o a mediano plazo agresiones contra comerciantes, capitanes de amigos, misioneros $u$ otros españoles que viviesen en tierra de indios o debiesen internarse en ella ${ }^{38}$. Cuando la enfermedad alcanzó Repocura, todos recordaron con inquietud que precisamente esta reducción había sido la instigadora del ataque sufrido por Francisco Marán en $1787^{39}$. La asociación de ideas se veía reforzada por el

36 Fray Ramón Redrado, Relacion de los Yndios de la dos Jurisdiciones de Chile y de Valdivia y de sus Inclinaciones errores, y costumbres. Misión de Arauco, 10-V-1775. AFCH, Vol. 3, f. 252. Esta práctica está ampliamente documentada para toda la región, y se encuentra confirmada por testimonios unánimes de otros misioneros jesuitas, franciscanos, autoridades religiosas y cronistas laicos: Olivares, 1864, p. 46; GuELL, 1982, p. 257; Sors, 1921, p. 85; Martínez de Bernabé, 1898, p. 104; Maran, 1990, p. 139; Miguel Ascasubi, Ynforme Chronologico... AFCH, Vol. V, ff. 86-86v.; Gómez de Vidaurre, 1889 [1789], p. 325; Carvallo Y GoyeneChe, 1876, p. 139; RAmíREZ, 1994, p. 89; entre otros.

37 Ascasubi, Ynforme Chronologico..., f. 86.

38 ZaVAla CEPEDA, 2008, pp. 238-239, también hace notar la relación entre enfermedad, brujería y violencia entre los mapuche, poniendo entre otros ejemplos el de la epidemia que estamos analizando; ver también el mismo libro acerca del contexto y de la sociedad mapuche en general durante el siglo XVIII.

39 En diciembre de 1787, Marán, obispo de Concepción, confiado en que el camino de la costa se encontraba expedito sin peligros para los españoles, decidió realizar una visita a Valdivia y las misiones intermedias, transportando su pontifical, cuyo valor sumado al de su equipaje y el de la comitiva, ascendía a más de treinta mil pesos. Luego de visitar a los feligreses en las reducciones de Arauco, Tucapel y Tirua, entre este sitio y el río Imperial fue asaltado en el paso de los Pinares por llanistas de las parcialidades de Boroa, Repocura y Alta Imperial, con motivo de no haberles solicitado permiso para realizar el viaje atravesando sus territorios. Los indios saquearon el equipaje y dieron muerte a dos dragones de la escolta, mientras el 
hecho de que una de las primeras víctimas de la enfermedad, su cacique Cayullanca, tuvo principal intervención en el ataque y saqueo de los bienes del prelado y conservaba parte del botín capturado en aquella ocasión:

Según menudamente me explica el Teniente Lisama que haido el este reconocim. ${ }^{\text {to }}$ quien añadi que como en Repucura aprieta con estrago el accidente, y entre los muchos que halli mueren fue uno Cayullanca principal motor según se dijo del insulto en los Pinales a este Ylustrisimo Señor Obispo, oio decir que aquellos Indios se quejavan mucho atribuiendo la Epidemia según su barbara ignorancia a echiserias dimanadas en venganza de aquel acontecimiento con otras ridiculeras dignas de desprecio. Ese dicho Cayullanca tenia aun barias alajas de las que quito entonces, y que decía Tranmaleu Casique de Repocura si su Ylustrisima les quitava la Peste harian por donde se le volviesen dichas prendas ${ }^{40}$.

Estas "alajas" escaparon a la campaña de recuperación ordenada por O'Higgins. La tarea se puso a cargo de caciques afines a la corona y sólo fue parcialmente exitosa, pues se consiguieron los objetos de oro y de culto, mientras que parte de la plata y casi toda la vestimenta quedó en poder de los atacantes ${ }^{41}$. La imposibilidad de recuperar todo el botín (especialmente las prendas de lujo que desempeñaban un importante papel como evidencia del éxito militar entre los mapuche ${ }^{42}$ ) pudo inducir la interpretación de que el obispo se aprestaba a obtener venganza recurriendo a la brujería, para desencadenar la muerte entre quienes lo agraviaron y la de Cayullanca antes que ninguna.

\section{LA COMPLEJIDAD DE LAS RESPUESTAS INDÍGENAS FRENTE A LA AYUDA OFRECIDA}

Ante la amenaza de desórdenes originados en la inquietud de los indígenas a raíz de la epidemia, que podrían poner en riesgo el Parlamento General que O'Higgins

\footnotetext{
prelado huía con su comitiva a esconderse en los riscos de Yupegue. Después de una serie de conmocionantes riesgos y alternativas, Marán y sus acompañantes conservaron la vida, debido a que los nativos partidarios de quitársela resultaron perdedores en un juego de chueca frente a los que se inclinaban por proteger a los españoles (Medina, 1906, p. 499).

40 Oficio de Pedro Nolasco del Río a Francisco de la Mata Linares. Los Ángeles, 31-VII-1792. AGI, Chile, 197, f. 253. En la documentación contemporánea al incidente se menciona que los principales atacantes fueron de Repocura. Oficio del Comandante de Arauco, Alfonso de Luna, al Comandante de Concepción, Pedro Quijada. Arauco, 1-XII-1787. Archivo Nacional de Chile (en adelante ANC), Capitanía General (en adelante CG), 707, f. 146), aunque en el Diario llevado por gente del entorno de Marán se menciona que los atacantes eran de Repocura y Boroa (Diario del Viaje emprendido p. ${ }^{a}$ la visita Episcopal dela Frontera de Chile, Valdivia y Chiloe por Tierra p. ${ }^{\mathrm{r}}$ el Yltmo Señor D.D. Francisco José de Maran. BNC-SBA, 37, f. 29). Respecto al líder principal del ataque, el que aparece mencionado es Victorio Analican de Repocura. Oficio de Ambrosio O'Higgins al Presidente Tomás Alvarez de Acevedo. Los Ángeles, 25-I-1788. ANC, CG, 707, f. 200; Carvallo y Goyeneche, 1876, p. 444; Pérez García, 1900, II, pp. 417-418). Cayullanca aparece mencionado en una negociación sobre la devolución de las alhajas. Oficio del Comandante de Nacimiento, Tadeo Ribera a Ambrosio O'Higgins. Nacimiento, 16-XII-1787. AN, CG, 707, f. 171.

41 Carvallo y Goyeneche, 1876, p. 445.

42 VILLAR - JiMÉNEZ, 2000, pp. 687-707.
} 
tenía planificado (y que debió postergar justamente debido a la peste), los españoles ofrecieron ayuda para sobrellevarla a las distintas reducciones. Por un lado, asistencia "material" y "espiritual", bajo la forma de médicos y medicinas, curas y misioneros; las medicinas incluían hierbas y baños que podrían considerarse parte de un tratamiento para quienes ya estaban afectados por la enfermedad; por otro, sugirieron medidas de prevención, principalmente el aislamiento comunitario y la evitación del contacto interpersonal e inter-grupal que se daba en los frecuentes convites ${ }^{43} \mathrm{y}$ en los funerales de los difuntos por la viruela.

\section{a. Sacerdotes y sangrías}

Las respuestas a las distintas propuestas españolas fueron diferentes. El rechazo al envío de sacerdotes y misioneros resultó unánime. A pesar de que se trataría de una presencia circunstancial mientras durase el brote y no de misiones permanentes, ninguna parcialidad quiso aceptarlos, arguyendo que no los necesitaban para nada. La negativa admite una explicación en términos político-ideológicos: los indios veían a los misioneros como parte de las fuerzas colonizadoras y sólo los aceptaban cuando convenía a sus intereses, con objetivos vinculados al intercambio y sin someterse al adoctrinamiento cristiano ${ }^{44}$. Pero además se basaba en una crítica a la terapéutica que estos últimos empleaban para tratar a los enfermos. El Intendente de Concepción Francisco de la Mata Linares reprodujo ese argumento nativo, cuando hizo explícito que los indios recelaban que los religiosos los matarían "con agua caliente" ${ }^{45}$. Si bien a primera vista esas palabras no tienen sentido para nosotros, lo cobran a poco que consideremos que los cirujanos o médicos sangraban a sus pacientes de pies y manos, haciéndoles introducir y mantener las extremidades en agua hirviente que actuaba como vasodilatadora y facilitaba la extracción hemática ${ }^{46}$. La sangría formaba parte de los tratamientos occidentales que recibían habitualmente los enfermos de viruela durante el siglo XVIII, junto con la administración de eméticos, purgantes y laxantes; dieta y restricciones al consumo de líquidos -0 , por el contrario, ingesta abundante de los mismos-; administración de sustancias minerales tóxicas como remedio y utilización continuada de la misma ropa de cama.

Pero entre los mapuche, el rechazo a la terapéutica empleada por los hispanocriollos no se debía en realidad al desconocimiento de las técnicas, pues sabemos por el jesuita Juan Ignacio Molina que gran parte de ellas eran conocidas desde tiempos pre-hispánicos: según el cronista, además de realizar sangrías, los indios consumían eméticos para provocar vómitos, diaforéticos para provocar la sudoración, y catárticos-laxantes débiles-, todos ellos tomados del reino vegetal:

\footnotetext{
43 VILLAR - JimÉnEZ, 2007, pp. 241-272.

44 Ver por ejemplo lo ocurrido al misionero Matud: Informe de Fray Juan Matud al Presidente del Reino de Chile sobre el estado de la reducción de Rucalgue. Rucalgue, 1-X-1761. AFCH, Vol. 1, ff. 327-334.

45 Oficio del Intendente de la Concepción Francisco de la Mata Linares al Presidente de Chile Ambrosio O’Higgins. Concepción, 19-X-1791. AGI, Chile, 197, f. 258v.

46 Alcedo, 1785, p. 644; Ferrer, 1904, p. 267.
} 
Antes del arribo de los españoles estaban ya en uso entre aquellos nacionales las sangrias, las ayudas, las calas, los vomitivos, los catárticos y los diaforéticos. Todos estos remedios tienen vocablos particulares en la lengua del pais. Extraen la sangre con la punta de un pedernal introducido en una varita, á la cual dan el golpe con el dedo índice apoyado sobre el pulgar. Este instrumento lo prefieren á la lanceta, porque lo creen menos expuesto a faltar. [...] Los eméticos, los purgantes y los sudorificos los toman casi todos del reino vegetal ${ }^{47}$.

Disponemos asimismo de una descripción de las circunstancias en que estaba aconsejado sangrarse durante el siglo XVII. El jesuita Diego de Rosales no deja lugar a dudas acerca de que los indígenas no empleaban esta técnica para tratar enfermedades graves, sino para aliviar moretones e hinchazones ${ }^{48}$. El expediente de 1791 lo confirma, pues sólo se menciona el uso de baños, reposo y cocimientos de hierbas, todo lo cual parece apuntar a combatir el estado febril de los enfermos, algo que si no los ayudaba, al menos no agravaba su situación ${ }^{49}$. La negativa al sangrado en momentos en que un paciente necesitaba de todas sus fuerzas se relaciona con el valor asignado a la sangre como una de las sedes del "pellü" o energía vital en la cosmovisión nativa ${ }^{50}$. Este es el motivo por el cual, a pesar de conocer la sangría y haberla practicado desde tiempos antiguos, la consideraban inadecuada en caso de viruela, lo mismo que la técnica de acelerar la pérdida hemática con agua caliente, que debilitaba al enfermo cuando este menos lo precisaba. De modo que el rechazo de la intervención de los misioneros deviene racional y práctico y se funda en un juicio desfavorable acerca de un procedimiento en particular.

\section{b. Yerbas y medicamentos}

En cuanto a las medicinas, hubo opiniones diversas. Muchos dijeron usar yerbas locales que ellos mismos encontraron para curarse; otros prometieron aceptar la ayuda farmacológica hispana, únicamente si la viruela entraba en sus reducciones. En Renaico, aseguraron "que en caso que les diese la peste recurrirían en busca de Medico, y Medicinas por que ellos no saben curarla" ${ }^{51}$. En cambio en Truf-Truf respondieron:

47 Molina, 1795, pp. 108-109.

48 GonZÁlez de NÁJerA, 1889, p. 49. "Sangradores no han menester porque no se acomodan a sangrar con lanzeta, y no reconocen enfermedad que necessite de Sangria, que todas dizen que son de vocado; ... Para alguna inchazon, golpe o caida, se sangran en la parte dolorída....": RosALES, 1877, I, pp. 167-168.

49 Dado el estado de la ciencia durante el siglo XVIII y aunque parezca contradictorio, lo más sensato en caso de contraer la viruela era mantenerse alejado de un médico que siguiera los preceptos hipocráticos o galénicos: la mayoría de los tratamientos recomendados colaboraban con la enfermedad para llevar al enfermo a la tumba, al punto que, en las formas benignas de la viruela, las personas que no recibían tratamiento tenían mayores posibilidades de supervivencia: ver al respecto GLYNN - GLYNN, 2005, p. 41; HopkINS, 2002, p. 33; WILLIAMS, 2011, p. 32.

50 BöNNING, 1995, pp. 115-116.

51 Oficio de Fermín Villagrán a Pedro Nolasco del Río. Los Ángeles, 27-VIII-1791. AGI, Chile, 197, f. 265. 
Que ia no nesecitavan de Medicinas por que en Su tierra habían encontrado algunas con que se curavan. Que la peste se havia inundado en su Tierra, y pocos quedaban a quienes les diese. [...] Y que en caso que dure hasta que calienten los soles avisaran y pedirán las Medicinas que se les ofrecian ${ }^{52}$.

La mayoría de las agrupaciones indígenas, en efecto, había desarrollado un tratamiento paliativo propio que incluía reposo, baños y el uso de hierbas:

Creo ia por cortado el contagio fundado en la distancia en que viven unos de otros, y no tanto en esto (aunque aiuda) pues en las mismas vivian quando se los introdujo la epidemia como en el método tan estraño y barbaro con que se medicinan los días de cama son según las Viruelas que les brotan se refriegan con canelo beben sisaña con Palque, concho de aniltún y se bañan mucho de modo que asi logran frenarla en su principio y que no produzca los estragos y propagaciones entre ellos que se experimento en el obispado, efectivamente a proporcion de su multitud no se ha visto maior destroso ${ }^{53}$.

En ese mismo oficio, se menciona el uso de cuatro infusiones o decocciones de plantas medicinales como remedios contra la viruela: friegas de canelo, cizaña con palqui, chilco (o chilca) y concho de Aniltún. Tanto el palqui como el chilco fueron empleados como febrífugos, lo cual es coherente con el uso de baños de agua fría: al parecer en ambos sistemas médicos -el galénico y el mapuche-el objetivo era atacar la fiebre, uno de los síntomas más notorios de la peste. La diferencia está en que en un caso se empleaban métodos agresivos para expulsar los humores que se consideraban generadores de la fiebre, mientras que en el restante la intervención era más suave y apuntalaba las defensas del enfermo.

En cuanto al canelo ("foye, boigne"), según Möesbach, las machis valoraban el uso de su corteza contra todo tipo de enfermedades:

La corteza del voigue, de indiscutibles propiedades tónicas, estimulantes y excitantes constituye la más afamada y aplicada panacea de la curandera araucana, la machi. Según ella no hay dolor ni enfermedad que resista la enérgica acción curativa de tan mágico remedio ${ }^{54}$.

En lo referente a la "Zizaña con Agua de Palqui", la decocción de la corteza interior del palqui (Cestrum parqui L'Her) era empleada como sudorífico contra las “calenturas malignas" 55 . El primer autor en consignarlo así fue el padre Rosales a mediados del siglo XVII, afirmando que se la empleaba para curar el tifus.

Usan de ella los indios en las calenturas colericas, ardientes, en la forma siguiente: toman sus baras estando frescas y con un cuchillito con grande suavidad quitan la corteza de la superficie, y luego van raspando sutilmente la segunda cortecita que tiene antes de llegar al corazon, y lo que sacaron raspando lo echan en una escudilla de agua, y cogen

52 Ibídem, f. 266v.

53 Oficio del Intendente de la Concepción, Francisco de la Mata Linares al Presidente de Chile, Ambrosio O’Higgins. Concepción, 19-X-1791. AGI, Chile, 197, ff. 276- 276v.

54 MöesBach, 1992, p. 98. Su uso para friegas parece aprovechar las características antisépticas de las hojas.

55 Ver Molina, 1986; Philipi, 1868, p. 284; Murillo, 1889, p. 158; Gusinde, 1936, p. 858. 
la corteza entre las dos palmas de las manos y la estriegan con fuerza hasta sacar de ella toda la virtud que pueden. Hecha esta dilijencia la cuelan y lo colado con un terron de azucar lo dan por las tardes a los enfermos que padecen fiebres colericas y sanguinas y en las calenturas pútridas de tabardete, y haze maravillosos efectos ${ }^{56}$.

En la actualidad, el tifus es considerado una enfermedad natural que se contrae porque "anda en el aire"; los remedios a emplear son: "reposo en cama, la ingesta de leche cruda de vaca, lavado más infusión de cuye, nalca y tilo y borraja" ${ }^{57}$. La combinación del palqui con la "zizaña" no aparece en la bibliografía salvo en la obra de Rodolfo Armando Philippi, quien menciona algunas variedades europeas de la planta empleadas como "aperitivas, febrífugas, tónicas" 58 .

Rosales y Möesbach se refieren a la decocción de las hojas de chilco para elaborar un diurético ${ }^{59}$. Adolfo Murillo le añade la propiedad de ser febrífugo, e incluso reproduce una receta para fabricar un sirope refrescante para las personas afiebradas ${ }^{60}$. Martín Gusinde menciona que en Panguipullli "se receta como remedio febrífugo una mezcla de hojas raspadas del Chilco, Palqui y Coyanlahuen" ${ }^{61}$.

\section{c. Medidas preventivas}

Acaso lo más interesante para nosotros sean las respuestas referidas a las medidas preventivas, puesto que en ellas se ponen en juego las concepciones etiológicas de la enfermedad: hubo quienes aceptaron llevar adelante en alguna medida las disposiciones de aislamiento y que parecerían consentir (aunque quizá el silencio no pueda ser siempre tomado como admisión) los principios de la teoría del contagio; en cambio, otros declararon explícitamente que tal contagio no existía, puesto que el mal era causado por accionar de un brujo. Veamos cada uno de los casos.

Respecto del segundo, en el mismo sentido de quienes creían que el obispo Marán podría haber generado la epidemia mediante hechicería, algunos de los grupos consultados, como fue el caso de la reducción de Quechereguas, respondieron invocando la actividad de las brujas:

Que tienen sus Yervas con que curarse, y que Padres Religiosos no necesitan, y que no podian dejar de ocurrir a los entierros por que no morían de peste sino de daño que las Brujas les hacían á los apestados ${ }^{62}$.

Ocurría lo mismo con la jurisdicción de la misión de Tucapel, donde el efecto de la viruela fue especialmente severo: era notorio que estos indios adjudicaban la enfermedad a la hechicería:

56 Rosales, 1877, I, p. 230.

57 Citarella, 2000, p. 338.

58 PhilipPI, 1868, p. 332.

59 Según Rosales, es la mejor medicina para el "mal de orina”, RosAlEs, 1877, p. 130.

60 Murillo, 1889, pp. 96-97.

61 Gusinde, 1936, p. 561.

62 Oficio de Fermín Villagrán a Pedro Nolasco del Río. Los Ángeles, 27-VIII-1791. AGI, Chile, 197, f. 264. 
Es presumible del caracter de estas gentes que profesan la novedad y sospecha, deque lo atribuian à otras causas, y principalmente los de Tucapen, que miran con indiferencia el contagio ${ }^{63}$.

Lógicamente, esa convicción conllevaba el desprecio por las medidas de aislamiento recomendadas por los españoles. Por otro lado, y apoyados en general en la teoría miasmática, los defensores españoles de la doctrina del contagio (ya fuera directo o indirecto) coherentemente recomendaban medidas profilácticas que suponían por un lado el aislamiento de las personas enfermas, a través de cuarentenas y cordones sanitarios, y por otro el abandono y fumigación de los lugares infectados. La recomendación fue aceptada por algunas reducciones:

Tratè del asunto con D. ${ }^{\mathrm{n}}$ Ramon Udalevi y los demas Caciques que correspondia, quiènes, [...] ofreciendome por su parte cerrar de firme algunos caminos extraviados, $\mathrm{y}$ que auxiliaran à los paseros [...], ayudandoles à la expulsion de los que de esta parte del Rio resultaban infectados ${ }^{64}$.

En Angol, el cacique Curinaguel aseguró que la peste no había ingresado en su reducción "y que esperaban no dentrase por el mucho cuidado que tienen de no consentir gente de otro lugar" ${ }^{65}$. En Nininco, donde tampoco había prendido la enfermedad, también juraron que "no iran a entierro de apestado ni comunicarian con gente de donde la aya" ${ }^{66}$. En Chacaico, el cacique don Pablo Millaqueque agradeció las recomendaciones y dijo que las cumpliría, porque "lo mismo le havia aconsejado su Padre antes de morir", aunque luego agregó que "ia no hacen juicio del Contagio por que esta por todas partes" 67.

\section{CONCLUSIONES}

Las diferentes respuestas que los indígenas dieron en esta ocasión y sus justificaciones resultan significativas a los efectos de esclarecer la serie de cuestiones que planteamos al comienzo. En todos los casos subsiste, claro está, la duda acerca de si las contestaciones fueron sinceras, o sólo "políticamente correctas", intentando calmar las prevenciones de las autoridades españolas y simulando obediencia, principalmente teniendo en cuenta que las recomendaciones hispanas también se orientaban a mantener la tierra en paz y detener los malones que se producían entre las distintas parcialidades. Pero no obstante, la diversidad de posiciones y las notables diferencias existentes entre reducciones vecinas expresan siempre una mentalidad pragmática y abierta, dispuesta a revisar las propias concepciones en busca de una respuesta social

\footnotetext{
63 Oficio de Manuel de Santa María Escobedo al Intendente de Concepción Francisco de la Mata Linares. Arauco, 25-VIII-1791. AGI, Chile, 197, f. 260.

64 Ibídem, ff. $259 \mathrm{v}-260$.

65 Oficio de Fermín Villagrán a Pedro Nolasco del Río. Los Ángeles, 27-VIII-1791. AGI, Chile, 197, f. $262 \mathrm{v}$.

66 Ibídem, f. $263 \mathrm{v}$.

67 Ibídem, f. 265.
} 
que minimizara el riesgo, priorizando la eficacia por sobre el riguroso "fundamentalismo" ideológico.

Puestos ante los ofrecimientos de auxilio, los distintos grupos indios los evaluaron cuidadosa y separadamente. Manifestaron un rechazo unánime al método de la sangría y a su aplicación por parte de los misioneros. Algunos aceptaron las medicinas con condicionamientos, aunque la mayoría optó por las propias. Y respecto de las medidas de aislamiento, muchos las llevaron adelante, confiando en su eficacia. Se trató entonces de una respuesta plural y a la vez selectiva, capaz de sopesar los beneficios prácticos de cada una de las alternativas disponibles y de escoger sólo aquellas que probaran mejorar las posibilidades de supervivencia de su propia población.

Vimos ya que durante el siglo XVIII, a ambos lados de la cordillera (tanto en las pampas como en la Araucanía) los indios habían comenzado a adoptar medidas de aislamiento y prevención, propias de alguna forma de aceptación del contagio. Podría pensarse en que las posturas al respecto "evolucionaron" desde una creencia "primitiva" en la brujería como causa eficiente de toda muerte juvenil, hacia una convicción uniforme en la existencia del contagio que hiciera olvidar las antiguas creencias; el expediente de 1791 muestra que no fue así, porque las distintas respuestas son estrictamente contemporáneas. Es temprano todavía para decir si las prácticas aislacionistas implicaron alguna suerte de abandono o modificación con respecto a las creencias en la brujería, así como de una visión personalista del origen del mal en favor de una naturalista. Sin embargo, de acuerdo con aquello que comparativamente muestran estudios etnográficos recientes, ambas pueden haber coexistido en la misma población y para la misma enfermedad, como ocurre contemporáneamente en el Haití rural, donde la gente cree que el sida puede contraerse de dos modos distintos, uno "natural" y otro "sobrenatural" 68 ; es decir, que se superponen una explicación "naturalista" y otra "personalista", tal como las definimos al principio.

Sí nos parece claro que en el caso de la viruela este tipo de política sanitaria nativa respondió a una visión práctica de la cuestión, basada en la eficacia y la contundencia de los resultados. Y que muestra - de nuevo- el carácter abierto a la innovación de la mentalidad indígena, previa evaluación acerca de la conveniencia de aquello que los representantes de la sociedad colonial tenían para ofrecer.

\section{REFERENCIAS BIBLIOGRÁFICAS}

Aguirre, Juan Francisco de

1949 "Diario del Capitán de Fragata de la Real Armada D. Juan Francisco Aguirre en la Demarcación de límites de España y Portugal en la América Meridional. Tomo I" [1793]. Revista de la Biblioteca Nacional. Buenos Aires, vol. XVIII, números 43 y 44, pp. 33-501.

\footnotetext{
68 'El sida natural se contrae por contacto sexual con alguien que 'tiene el germen'. El sida sobrenatural es enviado por alguien que desea la muerte del afectado", FARMER, 2002, p. 446. Farmer agrega que "estos dos esquemas causales principales (la brujería y la teoría del germen) se entrelazan en forma muy compleja y están sujetos a revisión", Ibídem, p. 449.
} 
Alcedo, Antonio de

1785 Medicina Domestica. Tratado completo del método de precaver y curar las enfermedades con el régimen y medicinas simples... Madrid. Imprenta de Sancha.

Bacigalupo, Anna Mariella

2001 La voz del kultrun en la modernidad: tradición y cambio en la terapéutica de siete machi mapuche. Santiago de Chile. Editorial Universidad Católica de Chile.

BLACK, Francis L.

1992 “Why did they die?” Science. Cambridge (Massachussets), vol. 258, n 5089, 11 December, pp. 1739-1740.

BOCCARA, Guillaume

1998 Guerre et ethnogenèse mapuche dans le Chili colonial. L'invention du soi. París. L'Harmattan.

BöNNING, Ewald

1995 El concepto de pillán entre los mapuches. Buenos Aires. CAEA.

Bueno, Cosme

1778 Parecer, que dio el doctor Don Cosme Bueno sobre la Representacion, que hace el Padre Fray Domingo de Soria para poner en pràctica la Inoculacion de las Viruelas. Lima. Imprenta de los Niños Huérfanos.

Carmichael, Ann G.

1991 "Contagion Theory and Contagion Practice in Fiftteenth-Century Milan". Renaissance Quarterly. Chicago, vol. 44, n 2, pp. 213-256.

Carvallo y Goyeneche, Vicente

1876 "Descripcion histórico-geográfica del Reino de Chile" [1796]. En Colección de historiadores de Chile y documentos relativos a la historia nacional. Tomo X. Santiago de Chile. Imprenta de la Librería del Mercurio.

Casanueva, Fernando

1992 "Una peste de viruelas en la región de la frontera de guerra hispano-indígena en el reino de Chile (1791)". Revista de Historia. Santiago, no 26, pp. 31-65.

2000 "Viruela y guerra en el sur de Chile a finales del siglo XVIII". En LovelL - Cook (coords.), Juicios secretos de Dios: epidemias y despoblación indígena en Hispanoamérica colonial. Quito. Ediciones Abya-Yala, pp. 203-226.

Citarella, Luca (compilador)

2000 Medicinas y culturas en la Araucanía. Santiago de Chile. Editorial Sudamericana.

Dillehay, Tom D.

2007 Monuments, Empires and Resistance. The Araucanian Polity and Ritual Narrative. Cambridge. Cambridge University Press.

Dobyns, Henry F.

1992 "Native American Trade Centers as Contagious Disease Force". En Verano Ubelaker (eds.), Disease and Demography in the Americas. Washington - London. Smithsonian Institution Press, pp. 215-222.

FALKNER, Thomas

1957 Descripción de la Patagonia y partes contiguas de la América del Sur [1774]. Buenos Aires. Librería Hachette. 
FARMER, Paul

2002 "Brujería, política y concepciones sobre el sida en el Haití rural”. Armus (ed.), Entre médicos y curanderos. Cultura, historia y enfermedad en la América Latina moderna. Buenos Aires. Grupo Editorial Norma, pp. 417-455.

FEBRÉS, Andrés

1765 Arte de la lengua general del Reyno de Chile, con un diálogo chileno hispano muy curioso... Lima. En la Calle de la Encarnación.

FERRER, Pedro Lautaro

1904 Historia general de la medicina en Chile: (documentos inéditos, biografías y bibliografias): desde el descubrimiento y conquista de Chile, en 1535, hasta nuestros días. Talca. Imprenta Talca.

FÖERSTER, Rolf

1993 Introducción a la religiosidad mapuche. Santiago de Chile. Editorial Universitaria.

Foster, George M.

1976 "Disease Etiologies in Non-Western Medical Systems". American Anthropologist. Washington, NS, vol. 78, $\mathrm{n}^{\circ}$ 4, pp. 773-782.

GiL, Francisco

1784 Disertación físico-médica, en la qual se prescribe un método seguro de preservar a los pueblos de viruelas hasta lograr la completa extinción de ellas en todo el Reyno. Madrid. Joachîn Ibarra, Impresor de Cámara de S.M.

GLynn, Jennifer - Glynn, Ian

2005 The Life and Death of Smallpox. London. Profile Box.

GómEz DE VidAurRe, Felipe

1889 "Historia Geográfica, Natural y Civil del Reyno de Chile" [1789]. En Colección de historiadores de Chile y documentos relativos a la historia nacional. Tomo XV. Santiago de Chile. Imprenta Ercilla.

Góngora Marmolejo, Alonso de

1960 "Historia del Reino de Chile desde su descubrimiento hasta el año de 1575" [1575]. En Crónicas del Reino de Chile, Edición y estudio preliminar de Francisco Esteve Barba. Biblioteca de Autores Españoles, vol. CXXXI. Madrid. Ediciones Atlas, pp. 75-224.

GonzÁlez de NáJera, Alonso

1889 Desengaño y reparo de la Guerra del Reino de Chile [1614]. Santiago de Chile. Imprenta Ercilla.

Guell, Segismundo

1982 "Noticia breve y moderna del Archipielago de Chiloé, de su terreno, costumbres de los indios, misiones, escrita por un misionero de aquellas isla en el año 1769-1770" [1770]. En Hanish, La Isla de Chiloé, capitana de rutas australes. Santiago de Chile. Academia Superior de Ciencias Pedagógicas, pp. 220-263.

Gusinde, Martin

1936 "Plantas medicinales que los indios araucanos recomiendan". Anthropos. Viena, vol. $31, \mathrm{n}^{\circ} 3 / 4$, pp. 555-571, y n $5 / 6$, pp. 850-873.

Hopkins, D. H.

2002 The greatest killer: Smallpox in History. Chicago - London. University of Chicago Press. 
JACKSON, Robert H.

2004 "Una mirada a los patrones demográficos de las misiones jesuitas de Paraguay", Fronteras de la Historia. Bogotá, vol. 9, pp. 129-178.

JONES, David S.

2003 "Virgin Soils Revisited". The William and Mary Quarterly. Williamsburg, 3a Serie, vol. $60, \mathrm{n}^{\mathrm{o}} 1$, pp. 703-742.

KeLton, Paul

2004 "Avoiding the Smallpox Spirits: Colonial Epidemics and Southeastern Indian Survival". Ethnohistory. Durham, vol. 51, n 1, pp. 45-71.

Laval R., Enrique

2010 "Disentería y absceso hepático en el Chile colonial y republicano. El Doctor Miguel Claro Vásquez". Revista Chilena de Infectología. Santiago de Chile, vol. 27, n 1, pp. 76-79.

LAVAL, Enrique

1964 "Patología de los Araucanos durante la Colonia". Boletín de la Academia Chilena de la Historia. Santiago de Chile, vol. XXXI, nº 70, pp. 5-42.

Maran, Francisco Joseph

1990 `Relación de las misiones de Chile y su frontera. Concepción, 8 de agosto de 1784. AN Jesuitas Vol. 96, fojas 81-108' [1784]. En Hanish, "Memorias sobre misiones jesuitas de 1794-1795". Historia, Santiago de Chile, no 25, pp.121-145.

Martínez de Bernabé, Pedro Usauro

1898 "La verdad en campaña. Relación histórica de la plaza puerto i presidio de Valdivia." [1782] En Biblioteca geográfica-hidrográfica de Chile, Segunda serie, publicada por Nicolás Anrique. Santiago de Chile. Imprenta Elzeviriana, pp. 43-218.

MedinA, José Toribio

1906 Diccionario biográfico colonial de Chile. Santiago de Chile. Imprenta Elzeveriana.

Mö̈sBACH, Ernesto Wilhelm de

1992 Botánica indígena de Chile. Santiago de Chile. Museo Chileno de Artes Precolombinas

- Fundación Andes - Editorial Andrés Bello.

MoLinA, Juan Ignacio

1795 Compendio de la historia civil del Reyno de Chile. Escrito en italiano por el Abate Don Juan Ignacio Molina [1787]. Parte Segunda. Madrid. Imprenta de Sancha.

1986 Ensayo de la historia natural de Chile [1810]. Santiago de Chile. Editorial Maule.

Murillo, Adolfo

1889 Plantes medicinales $d u$ Chile. Paris. Exposition Universelle de Paris.

Olivares, Miguel de

1864 "Historia militar, civil y sagrada de Chile" [1767]. En Colección de historiadores de Chile y documentos relativos a la historia nacional. Tomo IV. Santiago. Imprenta del Ferrocarril, pp. 1-402.

1865 "Historia de la Compañía de Jesús en Chile (1593-1736)" [1736]. En Colección de historiadores y documentos relativos a la historia nacional. Tomo VII. Santiago de Chile. Imprenta Andrés Bello.

PÉREZ García, José

1900 "Historia de Chile" [1810]. En Colección de historiadores y documentos relativos a la historia nacional. Tomo XXIII. Santiago de Chile. Imprenta Elzeviriana. 
PhilipPi, Rodolfo A.

1868 Elementos de botánica para el uso de estudiantes de medicina i farmacia en Chile. Santiago de Chile. Imprenta Nacional.

Pineda y Bascuñán, Francisco Núñez de

1863 "Cautiverio feliz y razón de las guerras dilatadas de Chile” [1674]. En Colección de historiadores y documentos relativos a la historia nacional. Tomo III. Santiago de Chile. Imprenta El Ferrocarril.

Quiroga, Jerónimo de

1979 Memorias de los sucesos de la Guerra de Chile [1690]. Santiago de Chile. Editorial Andrés Bello.

RAMírez, Fray Francisco Xavier

1994 Coronicón Sacro - Imperial de Chile [1805]. Santiago de Chile. Dirección de Bibliotecas Archivos y Museos - Centro de Investigaciones Diego Barros Arana.

Rosales, Diego de

1877 Historia general del Reyno de Chile, Flandes indiano [1674]. Tomo I. Valparaíso. Imprenta del Mercurio.

RuIz, Hipólito

1952 Relacion histórica del viage que hizo a los Reynos del Peru y Chile el botanico D. Hipolito Ruiz en el año de 1777 hasta el de 1788, en cuya época regreso a Madrid [1782]. Madrid. Real Academia de Ciencias Exactas, Físicas y Naturales.

Sors, Fray Antonio de

1921 "Historia del Reino de Chile, situado en la América Meridional, que hace relación de la población de los españoles en él: de las tierras de los Indios naturales, sus costumbres, y ubicación: del sistema conveniente para reducirlos a la obediencia de $\mathrm{Su}$ Majestad" [1780]. Revista Chilena de Historia y Geografia. Santiago de Chile, vol. XXXIX, n 43, pp. 168-199.

VALDivia, Luis de

1684 Arte y gramatica general de la lengva que corre en todo el Reyno de Chile... [1605]. Sevilla. Thomás Lopez de Haro.

VARGAS, Martín

1891 "Carta con que el Padre Martin Vargas dio noticia de su viaje al Padre Martín Bresser" [1628]. En Enrich, Historia de la Compañía de Jesús en Chile. Tomo I. Barcelona. Imprenta de Francisco Rosal, pp. 392-393.

VILLAR, Daniel - JiMÉNEZ, Juan Francisco

2000 "Botín, materialización ideológica y guerra en las pampas durante la segunda mitad del siglo XVIII. El caso de Llanketruz". Revista de Indias. Madrid, vol. LX, n 220 , pp. 687-707.

2007 "Convites. Comida, bebida, poder y política en las sociedades indígenas de las pampas y Araucanía". Anuario del IEHS. Tandil, n² 22, pp. 241-272.

WiLliams, Gareth

2011 Angel of Death: The history of Smallpox. New York. Palgrave Macmillan.

Zavala CEPEDA, José Manuel

2008 Los mapuches del siglo XVIII. Dinámica interétnica y estrategias de resistencia. Santiago de Chile. Editorial Universidad Bolivariana S.A. 